Article

\title{
The Institutionalization of Nature-Based Solutions-A Discourse Analysis of Emergent Literature
}

\author{
Rúben Mendes $^{1, *(\mathbb{D})}$, Teresa Fidélis ${ }^{1}\left(\mathbb{D}\right.$, Peter Roebeling ${ }^{2,3}\left[\mathbb{C}\right.$ and Filipe Teles ${ }^{4}(\mathbb{C})$ \\ 1 GOVCOPP: Research Unit on Governance, Competitiveness and Public Policies, \\ Department of Environment and Planning, Campus Universitario de Santiago, University of Aveiro, \\ 3810-193 Aveiro, Portugal; teresafidelis@ua.pt \\ 2 CESAM: Centre for Environmental and Marine Studies, Department of Environment and Planning, \\ Campus Universitario de Santiago, University of Aveiro, 3810-193 Aveiro, Portugal; peter.roebeling@ua.pt \\ 3 WEcR: Wageningen Economic Research, Wageningen University and Research, Droevendaalsesteeg 4, \\ 6708 PB Wageningen, The Netherlands \\ 4 GOVCOPP: Research Unit on Governance, Competitiveness and Public Policies, Department of Social, \\ Political and Territorial Sciences, Campus Universitario de Santiago, University of Aveiro, \\ 3810-193 Aveiro, Portugal; filipe.teles@ua.pt \\ * Correspondence: ruben.tiago@ua.pt; Tel.: +351-910-445-229
}

Received: 25 October 2019; Accepted: 9 January 2020; Published: 12 January 2020

check for updates

\begin{abstract}
The European Union quickly incorporated the concept of nature based-solutions (NBS), becoming a key promotor. This was achieved through financial support for both academic research and city implementations. Still, the processes of institutionalization are yet to be fully explored. This study aims at assessing how the scientific literature regarding NBS is addressing institutional aspects and how it is constructing the NBS narrative. This research is divided into two stages. First, it undertakes a quantitative analysis of the discourse, considering a set of preselected search terms organized into five categories: Actor, institutional, planning, policy, and regulation. Second, it adopts a qualitative analysis considering both a group of the most cited articles and of articles highlighted in the previous stage. The results indicate that the NBS concept is still shadowed by other environmental concepts such as ecosystem services. Despite being an issue promoted at the European level, the results of this exercise express the lack of concrete planning and policy recommendations, reflected by the absence of terms such as "planning objectives". This pattern occurs in all other major categories, being the institutional category the least mentioned of all five categories. The results highlight the need to address both policies and planning recommendations more concretely, studying the institutional arrangements able to promote NBS.
\end{abstract}

Keywords: nature-based solutions; institutionalization; spatial planning; discourse; public policies; global change; institutional setting; adaptation

\section{Introduction}

Urban areas are facing strong challenges, especially on environmental issues, with understandable impacts on both society and the economy. In fact, more than $70 \%$ of the European population lives in urban areas as compared to $50 \%$ for the overall world population. Urban population is expected to increase to near 70\% globally by 2050 [1]. Moreover, and particularly in Europe, extreme climate events are expected to be more frequent, with heat waves and heavy rainfall events to pose an even larger challenge to cities [2], in particular, considering their vulnerability associated with, amongst others, 
construction density [3,4]. Biodiversity and the health of ecosystems are in threat when exposed to such extreme conditions [5,6] and, therefore, adaptation is unavoidable.

Impacts coming from climate change have received increased attention and recently was observed as a shift from hard "grey" infrastructures to more "soft" and natural solutions [7]. One of the key elements to explain this shift is the difficulty to promote sustainability and biodiversity where natural elements are lacking [8]. Therefore, balancing the urban development, accommodating even more people in fewer spaces, and the ecological equilibrium of urban spaces, is probably the biggest challenge for urban planning [9]. The European Commission (EC) is addressing these multiple challenges by stressing the importance of accomplishing job creation and increased competitiveness while managing and avoiding environmental problems [10].

Green and blue spaces and, recently, nature-based solutions (NBS) are key elements in urban contexts and their contribution to support, not only biodiversity but also human conditions, is being increasingly considered. These same worries, but also opportunities are embedded in Horizon 2020, as reflected in the financial support given by the European Commission (EC) to multiple NBS projects since 2015 [11]. By promoting renaturalization, the EU Biodiversity Strategy for 2020 [12] is also responsible for promoting different policy approaches. Another key indication provided by the European Union (EU) is expressed in the Green Infrastructure Strategy [13], in which nature is interpreted as a natural component and simultaneously as an economic instrument able to promote a 'greener economy' [14]. Indeed, multiple perspectives exist on how nature can help to solve environmental and societal problems [15].

Hence, we are witnessing a scientific effort to find solutions that encapsulate all these domains using nature. NBS emerge, in this context, as a new body of research that is promoted mainly by the EC and that builds upon older concepts as "ecosystem-based approach" or "ecosystem services" [16]. The last decade emphasized this idea, with multiple strategies and legal documents coming from the European institutions on these topics. The embedment of NBS and related concepts in urban agendas will probably give Europe conditions to command the adaptation process with new policies, regulations and plans [17].

As stated in the Eklipse project report [15], NBS allows finding solutions to tackle multiple challenges, within different dimensions. These challenges can be related to environmental dimensions such as climate resilience or water management, but alsoto economic and social dimensions ranging from green economy to planning and governance issues. In the context of planning exercises, the concept of NBS has also been associated with concepts such as co-design and co-management, where the role of stakeholders becomes central $[18,19]$. The multidisciplinarity required to foster NBS demands robust mechanisms of knowledge transfer between academics, practitioners, and civil society. Yet, NBS suffers multiple incorporation difficulties already observed in other environmental concepts [20]. The processes of institutionalization are not clear, and the institutional arrangements adopted to implement this concept are still to be widely explored. This is mainly due to most of the research about NBS being focused on topics such as environmental indicators, while the roles of planning, governance, policy and institutions, and the subsequent implications, are widely ignored [21,22]. This overlaps with the fact that most of the research regarding NBS works with limited case studies, increasing, therefore, the difficulties to spread the knowledge to other contexts [23].

This study aims at assessing how the scientific literature regarding NBS is addressing institutional aspects and how it is constructing the NBS narrative. This research is divided into two main phases. First, it undertakes a quantitative analysis of the discourse, considering a set of preselected search terms organized into five categories: Actor, institutional, planning, policy, and regulation. Second, it adopts a qualitative analysis considering both a group of the most cited articles and a group of articles highlighted in the previous stage. The remainder of this paper is structured as follows: The next section addresses the historical background of the NBS concept. Section 3 explores the methodological approach. Section 4 presents the results with the associated discussion presented in Section 5. Finally, Section 6 of the article presents the conclusions. 


\section{Historical Perspective}

\subsection{Nature-Based Solutions: Definitions}

Nature-based solutions appeared as a concept in the years 2000's and brought attention to proactive managing nature towards improving urban ecosystem services and benefitting from them [24]. The relation of NBS with other "similar" concepts is evident, as it tries to combine other concepts already present in literature-such as ecosystem services, green/blue spaces, green/blue infrastructures or ecosystem-based approaches [25]. The construction of this "narrative" has been mainly stimulated by the EC through financial incentives for research related to these subjects [16,26]. As Escobedo et al. [27] (2018: p. 4) refer "as part of the evolution of these metaphors, the adopted terminology has changed and become increasingly institutionalized".

Although the term "nature-based solutions" is almost self-explanatory, the different definitions that arose are of utmost importance to understand the contextual background and the different visions underpinning the NBS concept. Ideas and concepts construct the discourse, for example, in policy documents, and those tend to express the main paradigm at a certain point [28]. On the one hand, Cohen-Shacham et al. [24] (2016: p. 14) define NBS as "actions to protect, sustainably manage and restore natural or modified ecosystems that address societal challenges effectively and adaptively, simultaneously providing human well-being and biodiversity benefits". This definition promoted by the International Union for Nature Conservation (IUCN) has a focus on nature itself and reinforces the importance of dealing with social affairs using these types of solutions. On the other hand, the European Commission [11] (2015: p. 7) defines NBS as "living solutions inspired by, continuously supported by and using nature, which are designed to address various societal challenges in a resource-efficient and adaptable manner and to provide simultaneously economic, social, and environmental benefits". This definition appears to be more "political" and centered in what mankind can benefit from using nature as a source of solutions-therefore more related to economy and market-orientation. These two ideas, one more focused on nature and the other more focused on humans, exemplify the different visions on what NBS are and how they should be used. Frequently these different interpretations are also dependent upon the area of research-i.e., ecologists tend to refer to NBS by having living organisms, while, in some cases, engineers refer to NBS by having infrastructures that mimic nature [7]. Despite the multiple possible definitions, one of the major advantages of NBS is the possibility to move towards a more social and nature conservationist oriented approach, combining both necessities [16]. Pointing out the relation of NBS with other concepts, Maes \& Jacobs [14] (2017) adopted a definition of NBS as "any transition to a use of ecosystem services with decreased input of non-renewable natural capital" (See other definitions of NBS in [29]).

Using the knowledge that has been promoted by European Commission projects, we can foresee common goals between projects and help incorporate those goals into policy, at every policy cycle, considering that each gives different solutions to different problems. As mentioned before, the major strength of NBS, and its innovation component is the incorporation of the societal domain-building the conceptual bridge between ecosystem services, day-to-day social concerns, and governance [29].

\subsection{Nature-Based Solutions: Policy and Planning}

The role of cities, as a geographic unit, is undoubtedly important in making NBS part of the usual procedure followed during planning activities. Cities' (municipal) responsibilities, using their political and social legitimacy, are crucial in areas as land-use planning and green/blue infrastructure management. They can, not only actively build and manage multiple natural areas but also promote natural solutions using tools such as the municipal land-use plan, as well as financial, political, and other planning tools. Creating the right context, which includes the institutional arrangements able to promote NBS in each individual case, is playing a decisive factor in the local sustainability agenda [30]. The changes in governance, more closely related to climate change adaptation processes, are already seen in multiple documents at the local scale [31]. 
The NBS agenda, and how it can help to face the environmental challenges requires a specific way of planning towards adaptation that is, simultaneously, holistic, clear, and able to involve more citizens in the decision making process, as well as foster social innovation [31]. This innovation can be, as well, the motivation for the required institutional change and for the newer forms of governance, such as transition management or strategic niche management [32]. Despite the evident importance of innovation, it is equally important to incorporate traditional knowledge about planning and public policies [16]. Multiple NBS projects are being promoted by the EC (see NBS projects network; https://ec.europa.eu/research/environment/index.cfm?pg=nbs), and these are essential to prove the value of NBS to stakeholders and decision-makers-providing quantitative evidence about the influence of NBS on multiple local indicators [33,34]. Yet, it is not only important to promote research about indicators as well as, present/future impacts, but also to promote the study of tools able to operationalize these concepts (legal requirements for example) that are adequate to influence policy and planning. This requires knowledge on how to deal with different perspectives and interests while the demand for land is growing. Ultimately, the adequacy of institutional settings is essential to achieve this goal. The need for good examples, commonly called "champions", presenting planned and implemented NBS is key given the importance of ( $\left.\mathrm{co}^{-}\right)$creating and maintaining these natural infrastructures. Additionally, these can help with multiple comparative works between these natural infrastructures and the traditional "grey infrastructures" [7,33].

The overall political agenda is not only promoted by higher institutions, such as the European Commissions but is also highly dependent on political cycles (typically $4-5$ years) and the social values that are constructed at a certain moment. Promoting a focus on NBS planning is often difficult to accommodate with high social and economic demands and with a fast evaluation of the political options. To provide a shift to more natural solutions in urban environments, it is essential to emphasize the importance of larger political commitments, that, preferably, involve citizens and other stakeholders as to, protect the long-term benefits and allowing for strategies that are extendable in time. As Davies et al. (2015) [35] refer, many green policies at the municipal scale need to be institutionally and politically flexible to accommodate the natural political shifts resulting from elections. Even within municipalities, it is often difficult to communicate between departments, as they have their own language, skills, and responsibilities [33]. Hence, attention must be given to this "intracommunication", enabling the different departments, to build NBS type solutions together [36].

Research focused on how ecosystem-based approaches, in which NBS is included, can help to embed these issues in initial policy phases, in particular through urban planning [37]. Zölch et al. (2018) [38] showed that the NBS concept is better understood by the scientific community than by local administrations, which tend to slowly adopt scientific knowledge. For implementers, local authorities and urban planners in most cases, it is hard to follow up and assimilate the intensity of scientific production on NBS. Outside the scope of research projects implementation, or of cases with a strong history on green or blue spaces management, the change of planning paradigm by incorporating NBS can become quite a challenge for a regular city. By facilitating the transfer of new knowledge and the construction of common narratives, co-design and participatory planning initiatives may contribute to overcoming frequent institutional blockages for the implementation of NBS [22].

Therefore, we are facing an evident challenge supported by the lack of established pathways to promote NBS in urban governance, fully enabling the reflection about the planning and design needed for these solutions [39]. Thus, the production of scientific knowledge must also focus on the importance of incorporating new issues in the urban planning context and traditional forms of governance [40]. At the municipal level, multiple barriers are identified, including the legal framework, the division of departmental responsibilities and related communication [4,31]. Yet, the understanding of both institutional and normative contexts is essential to foster NBS and develop pathways to incorporate those in a capable and resilient manner for each urban context. In this context, public policies have a decisive role in the process, by contributing to possible pathways that enable the incorporation of NBS and simultaneously overcoming the typical barriers [29,30,41-43]. 


\section{Research Methodology}

The research in this article was conducted in two stages. First, it undertakes a quantitative analysis of the discourse, considering a set of preselected search terms organized into five categories (see Section 3.1). Second, it adopts a qualitative analysis considering both a group of the most cited articles and a group of articles highlighted in the previous stage (see Section 3.2).

\subsection{Bibliometric Analysis}

The initial stage of the research was based on a Scopus database search (www.scopus.com), using the search term "Nature-based solution", considering the article title, abstract, and keywords. Later were added the terms "Land-use", "Planning", and "Regulation" within the NBS database. Only peer-reviewed articles, written in English, until 2018 were considered; reviews, conference papers, and others were excluded. This method allowed the identification of 142 papers. A database was constructed with all the publications and a preliminary statistical analysis was conducted with the number of publications per year. Following, the same database was used, excluding repeated articles and papers not findable. This database comprises the input data for the software "VosViewer" (www.vosviewer.com) allowing a deeper analysis in aspects such as geographical distribution, citation relations between authors, and occurrence of keywords [44].

The VosViewer software uses the database, in this case, an excel file directly downloaded from Scopus and then generates maps based on the visualization of similarities technique (VOS) [44]. These maps are then visualized using the same software on a distance-based network map where clusters are formed and relationships between elements are represented both by their distance and by a direct line. Since the distance between elements reflects how strong their relationship is, the spatial distribution of elements may be inequal and some labels may be missing due to overlap issues. Yet, the easy formation of clusters facilitates the reading, by identifying different schools of thought that are important for this particular study. The technique is based on a co-occurrence matrix generated by the software out of the database [44]. For the study of concepts embodying strong interdisciplinary dimensions, the use of network analysis has proven to be especially useful [45] and has already been used in other studies within the environmental scope [46]. Through this technique, and for this study, three types of maps were generated: A co-authorship map between countries; a co-occurrence map between authors' keywords, and a co-citations map among the authors with more citations. The visual arrangement of this information facilitates the analysis that would otherwise be much more difficult to perceive.

\subsection{Quantitative Analysis}

The second stage of the research was based on, first, a quantitative analysis of the articles identified in stage 1, and, second, a brief qualitative content analysis of a set of selected articles. This part had a similar criterion for the selection of the articles, considering only the documents classified as articles, excluding reviews, conference papers, and repeated papers.

Many authors refer to discourse analysis as an important tool to understand the institutionalization of emergent subjects [47]. Following this criterion, an analytical framework was developed that is based on a set of words to be identified in the selected papers. Due to the interest in understanding how scientific literature about NBS is addressing the different issues of institutions, actors, policy, planning, and regulations, five major categories of words were defined around these words (see Figure 1). Each major category of words has multiple terms associated, and each term was searched individually with the help of the data analyses software WEBQDA (https://www.webqda.net). The research considered the relations with other close terms-for example, in the reference "institutional", the search was conducted in order to consider other words with the same origin as "institutions". The mechanic of the software is similar to the logic of search in the scientific database-in this example, the search was "institute *". When considering the counting of each term, the option was to engage in a more open approach that included all the terms that generate doubts—only excluding the ones with evidence of 
total disagreement with the research topics. A typical case was "planning the case study" - where the term "planning" was excluded from the analysis.

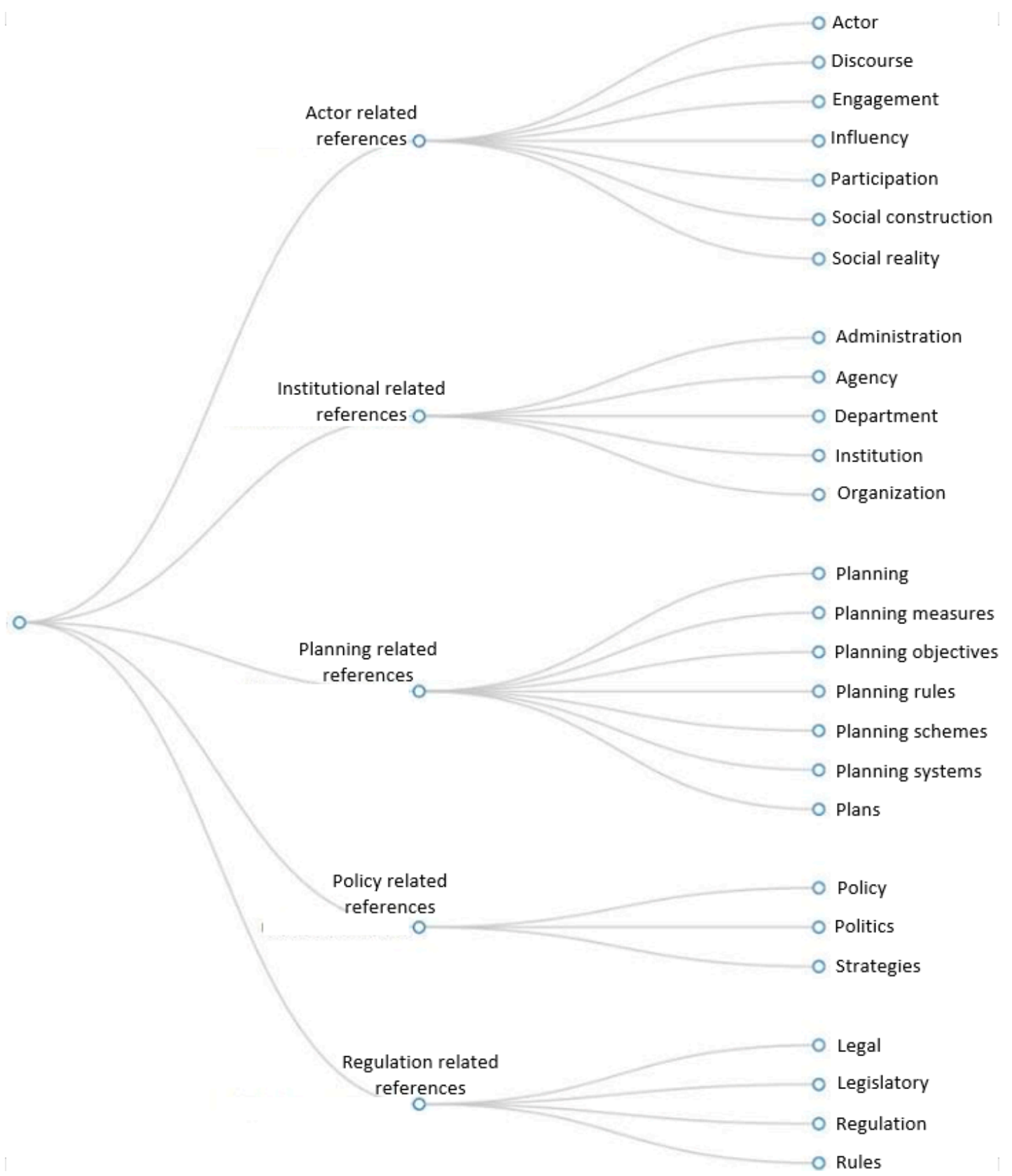

Figure 1. Diagram of terms by major categories: Actor, institutional, planning, policy, and regulation.

Each term was individually accessed to understand where it is placed in the different sections of the article and if it is related to the subject in the study. Six main sections of a typical article were considered: Introduction, state of art, methodology, results, discussion and conclusions. Whenever the article did not follow those specific sections, each term was incorporated in one of the six sections considered, by accessing the correspondence of that part of the article with one of the six sections referred before. This was obtained by, for example, considering the conceptual framework as part of the methodology or the recommendations as part of the conclusions. Whenever one section of the article was together with another section (e.g., the discussion together with the results or conclusions), an effort was made to understand where that specific term could be suitable in one of the six sections selected (avoiding double counting). Whenever the document was not divided into the sections 
described above (e.g., when the discussion was integrated into several subtopics), an attempt was made to fit the terms into one of the sections.

\section{Results}

A total of 142 articles were identified. Exclusion of repeated, not found, and papers with a nonconforming structure resulted in a total of 132 articles that were considered in the bibliometric (Section 4.1) and quantitative (Section 4.2) analysis.

\subsection{Bibliometric Analysis}

The temporal evolution of publications addressing "nature-based solutions" is shown in Figure 2. NBS as an issue was first mentioned in 2012, with only two articles being published that year. As of 2015, the number of articles on NBS began to increase, having an accelerated growth to more than 100 by the year 2018. The results show that NBS, as a concept, had a "late start" with the incentives referred in the Introduction having their influence recently. As NBS is a recent study area, although with knowledge already built from other concepts ("inside the umbrella"), the number of publications is expected to continue to increase.

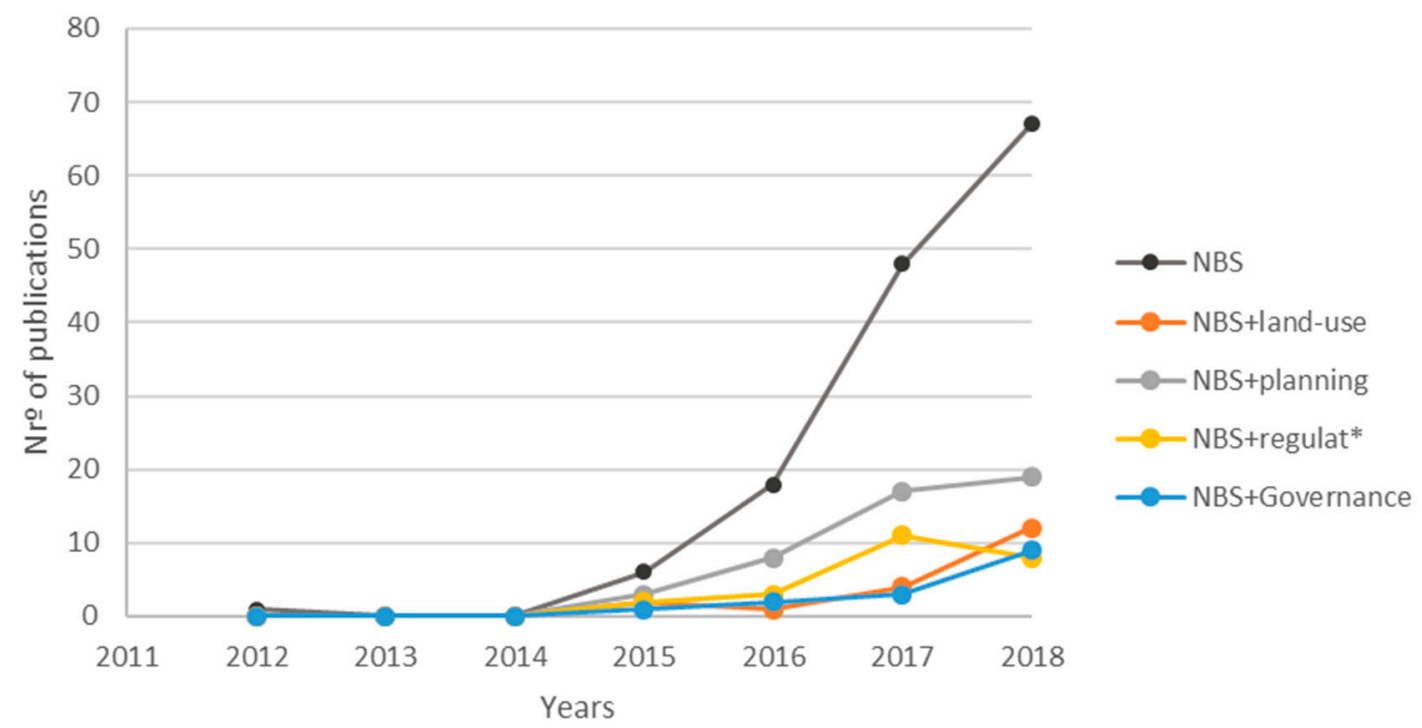

Figure 2. Temporal evolution of the number of articles addressing the issue of nature based-solutions (NBS); NBS and land-use; NBS and planning; NBS and regulations; and NBS and governance.

The search for the relation with other terms, such as governance, planning, regulation, and land-use proves that these questions had a small increase in recent years, which is not yet following the same accelerated growth shown by the general NBS term. It can be interpreted as evidence that despite the issues revealed in these four concepts are presented since the beginning of this research topic (2015), the research focus on these topics is not growing accordingly.

Regarding the spatial distribution of publications on NBS, they are more concentrated in European countries-as expected due to the strong stimulus given by European institutions. Figure 3 shows the co-authorship relations between the top 20 countries with more publications on NBS. The diameter of spheres is related to the number of articles and the links represent the shared authorship of articles. Outside Europe, the United States and China are the countries with most publications and author relationships. In the European context, Sweden, United Kingdom, Germany, Italy and, to a lesser extent, The Netherlands, should be highlighted—not only, due to numbers of articles, but also for the strong author relations with other countries as their central place in the figure shows. 


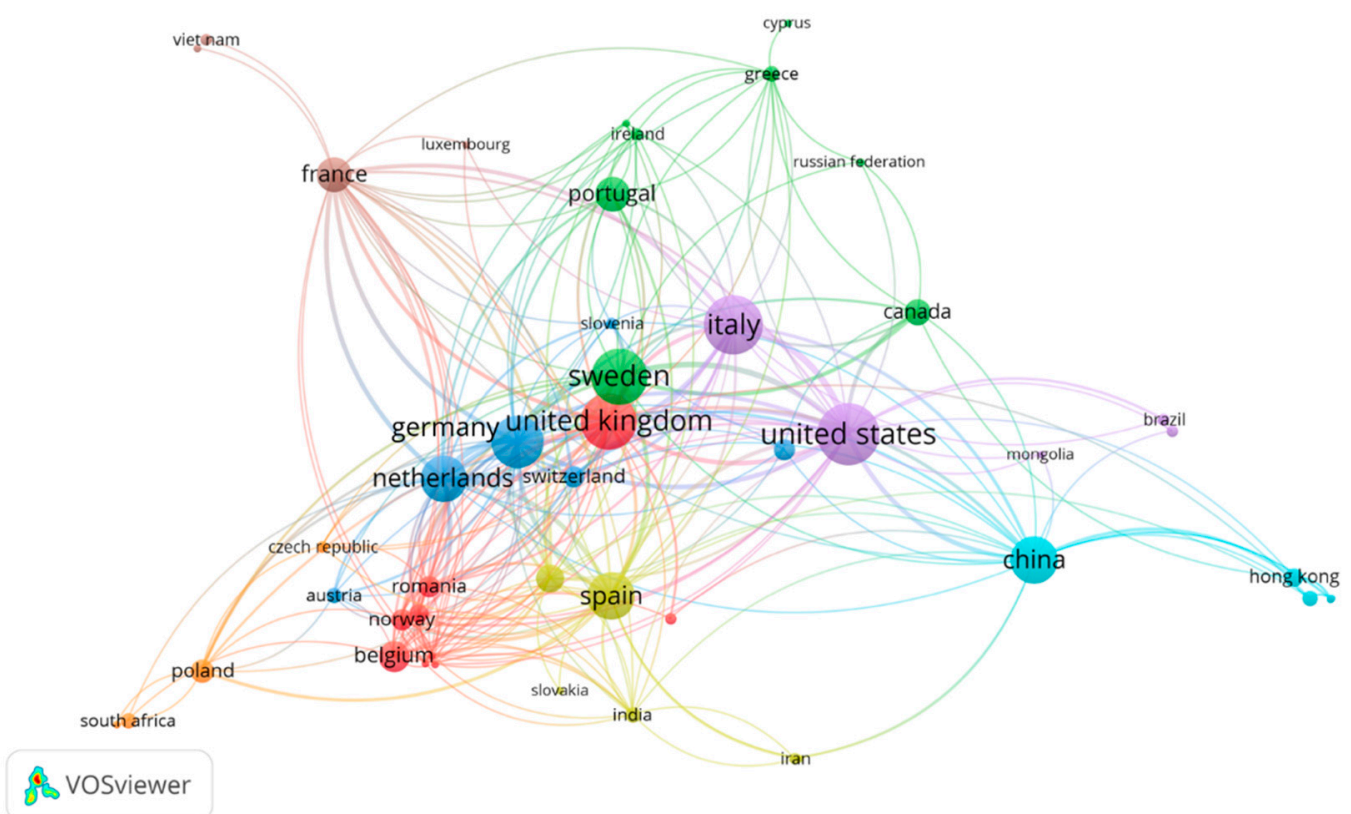

Figure 3. Relation of articles co-authorships between countries-the dimension of each sphere represents the number of articles with authorship from that country. The thickness of the connections represents the number of shared authorships between the two connected countries. Software: VOSviewer.

Albeit the predominance of European countries, and the expected exceptions of United States and China results show three Mediterranean countries in the top 10 with most article authorships (Italy, Spain, and Portugal). In fact, Italy is the country with third-most publications, only surpassed by United States and United Kingdom. Overall, countries as United Kingdom, Germany, Sweden, United States, and Netherlands play a central role in terms of both numbers of publications and co-authorships shared with other countries and, therefore, can be considered as the 'leading forces' in NBS research and discourse.

Figure 4 shows the authors' keywords and connections between those keywords. Nature-based solutions present strong relations with terms such as green infrastructure and ecosystem services. In the second order of importance, NBS is heavily connected with the terms climate change and sustainability. The occurrence of terms directly related to policy, regulations, institutions, actors, and planning, is only observed twice in the keywords "governance" and "land management" —albeit with very small importance as compared to the keywords mentioned before.

The number of citations and their relationship often demonstrate the importance of each author in the overall discourse. Figure 5 presents the citation relations between authors with at least 10 citations. The weight of the spheres represents the number of citations for each author. VOSviewer condenses authors with more citation relations (either 'cite' or 'be cited by' that author)—for example, Kabisch N., Frantzeskaki N., and Pauleit S. demonstrate close citation relations constituting a separate cluster. These clusters tend to indicate that closer authors share the authorship of works more commonly. Moreover, these clusters often represent different approaches and different "schools" within the NBS subject and, therefore, often different discourses. Consequently, we performed a deeper analysis of the articles with more citations among the selected database. These articles, due to their high volume of citations, can be considered as more influential in the discourse and metaphors regarding NBS. 


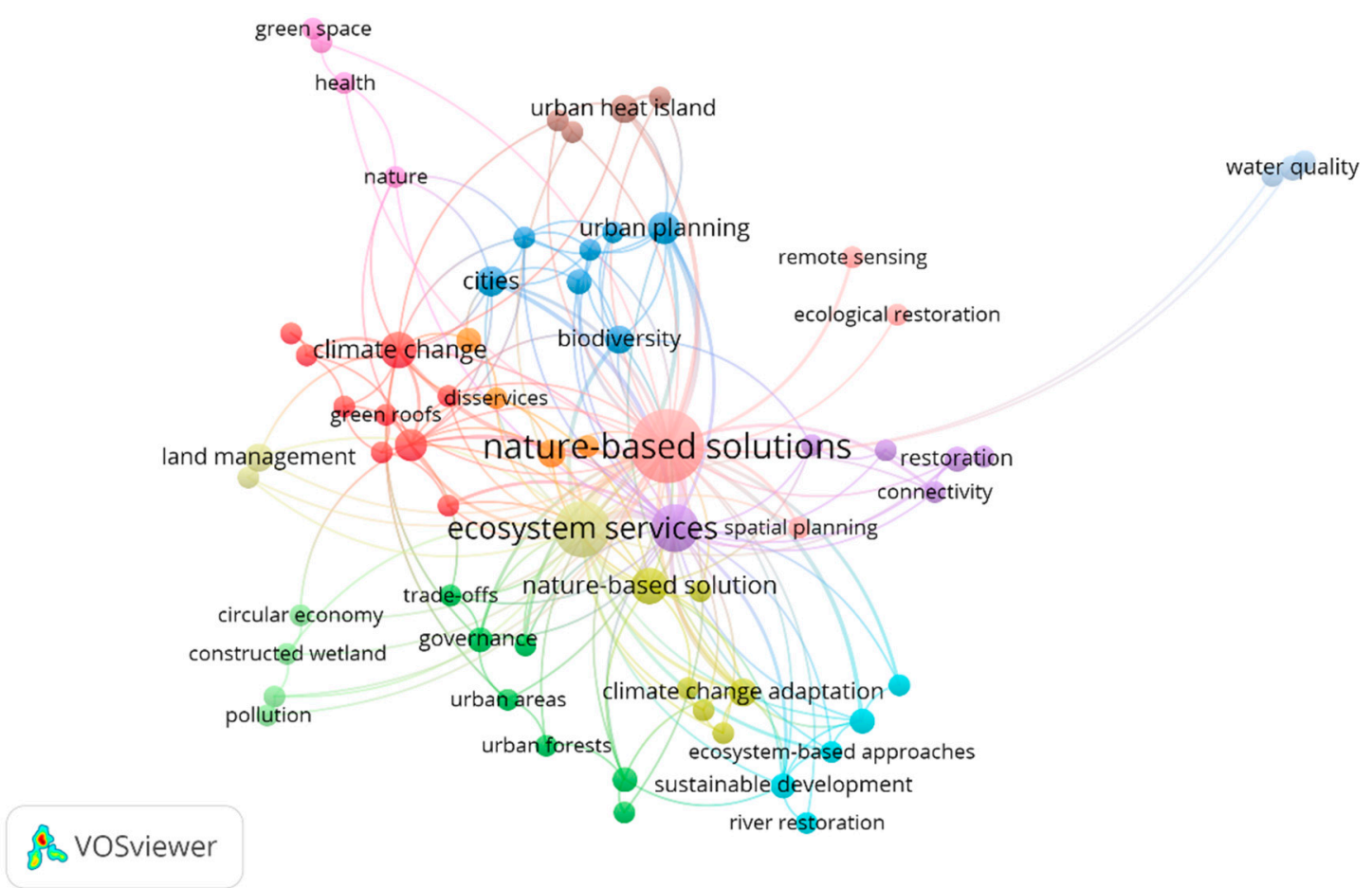

Figure 4. Relation of co-occurrence between authors' keywords, appearing at least twice. The dimension of each sphere represents the number of times that a keyword appears. The thickness of the connections represents the number of times that two keywords occur together. Software: VOSviewer.

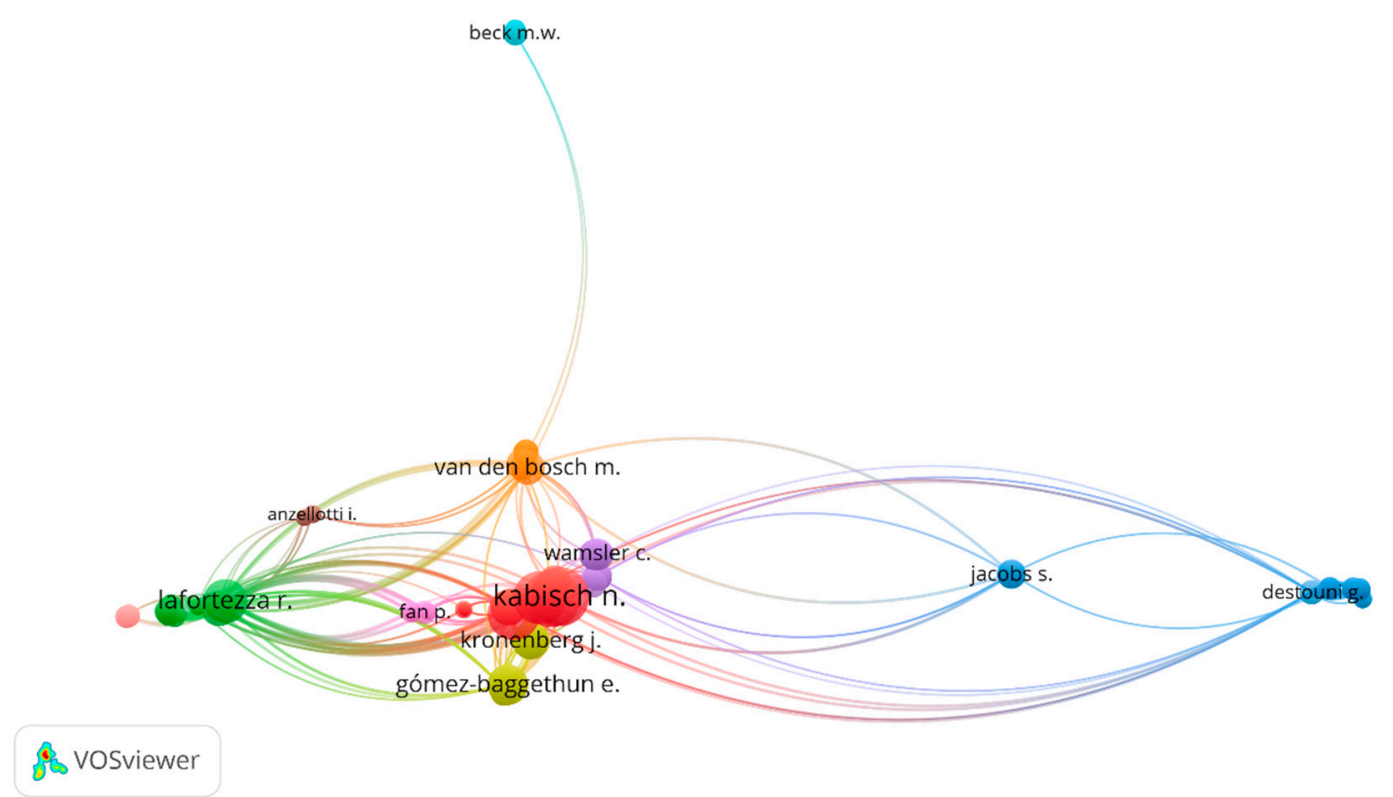

Figure 5. Co-citation relations between authors with at least 10 citations, the size of the spheres represent the number of citations for each author. The thickness of the connections represents the frequency of citations between those two authors. Software: VOSviewer.

Kabisch et al. (2016) [33] uses an expert workshop about NBS and climate change mitigation and adaptation in urban areas to point-out potential barriers and opportunities. In this article, the lack of indicators for measuring the effectiveness of NBS for climate change mitigation and adaptation is recognized as a possible difficulty related to the knowledge gaps on their effectiveness in the urban context. As the authors refer, "strategic planning of green infrastructure will be instrumental to avoid 
piecemeal approaches and instead to green and blue spaces in the city" (Kabisch et al., 2016, p. 6) [33]. Governance is considered a crucial factor by experts and, in particular, the difficulties related to the disconnection between short-term action and long-term goals influenced by the political cycles. The implementation and maintenance of these solutions after the projects, which are happening in multiple European cities reveals itself as a potential barrier. Nonetheless, as is referred by Kabisch et al. (2016, p. 7) [33] "The concept of NBS is expected to shift the discourse in policy and science from focusing on barriers to offering solutions ( ... )". In this context, governance is considered as both a potential barrier and an opportunity, as institutional arrangements need to be adaptable to new concepts such as NBS.

In a systematic review of reviews, van den Bosch \& Ode Sang, (2017) [48] stress the potential importance of NBS on human health and the lack of literature on this subtheme under the NBS umbrella. It is suggested to integrate health in the NBS approach as "It would showcase the need for analysing health issues and outcomes in environmental-related projects, both within science, and assessment and policy processes" (van den Bosch \& Ode Sang, 2017, p. 9 [48]).

The article by Maes \& Jacobs, (2017) [14] is one of the pioneer articles on NBS, where the relations with ecosystem services and policies, through the European Union is highlighted. This relation with ecosystem services is best expressed by the definition of NBS promoted by these authors: " $(\ldots)$ any transition to a use of ecosystem services with decreased input of non-renewable natural capital and increased investment in renewable natural processes" (Maes \& Jacobs, 2017, p. 3) [14]. The vision of NBS promoted by this definition engages with a broader interpretation of the term which can go from agricultural and forestry applications to the urban context.

\subsection{Quantitative Analysis}

In the current study, the approach to discourse analysis was made through five main categories of terms (namely actor, regulation, planning, policy, and institutional, see Figure 1). Each major family was then divided into multiple related terms and their frequency was measured in total and in each article section (i.e., Introduction, State of art, Methodology, Results, Discussion, and Conclusion).

In total, the Discussion section, both in planning and policy categories, present more references than any other section studied, while, less relative importance is given to institutional and actor categories of terms as an overall (see Figure 6) where terms related to institutionalization are included.

Considering the distribution of terms by the article sections, each major category of terms presents a similar pattern (mainly mentions in the Introduction section and, in particular, Discussion), although with very different total frequencies (see Figure 6).

These results show that specifically the policy discourse promoted by the scientific literature is heavily centered in the Discussion section-with a mean value of almost 4.5 citations per article. In opposition, actor and institutional categories, occur much less frequently, being the only section with a mean value higher than one citation the Discussion.

Another relevant aspect to consider is the frequency of each individual term (See Figure 7). Here, policy, planning, and strategy stand out as the most frequent terms studied with a mean value of more than five references per article. By contrast, terms considered more specific within the planning discourse, such as planning rules, planning measures, or planning objectives are absent. 


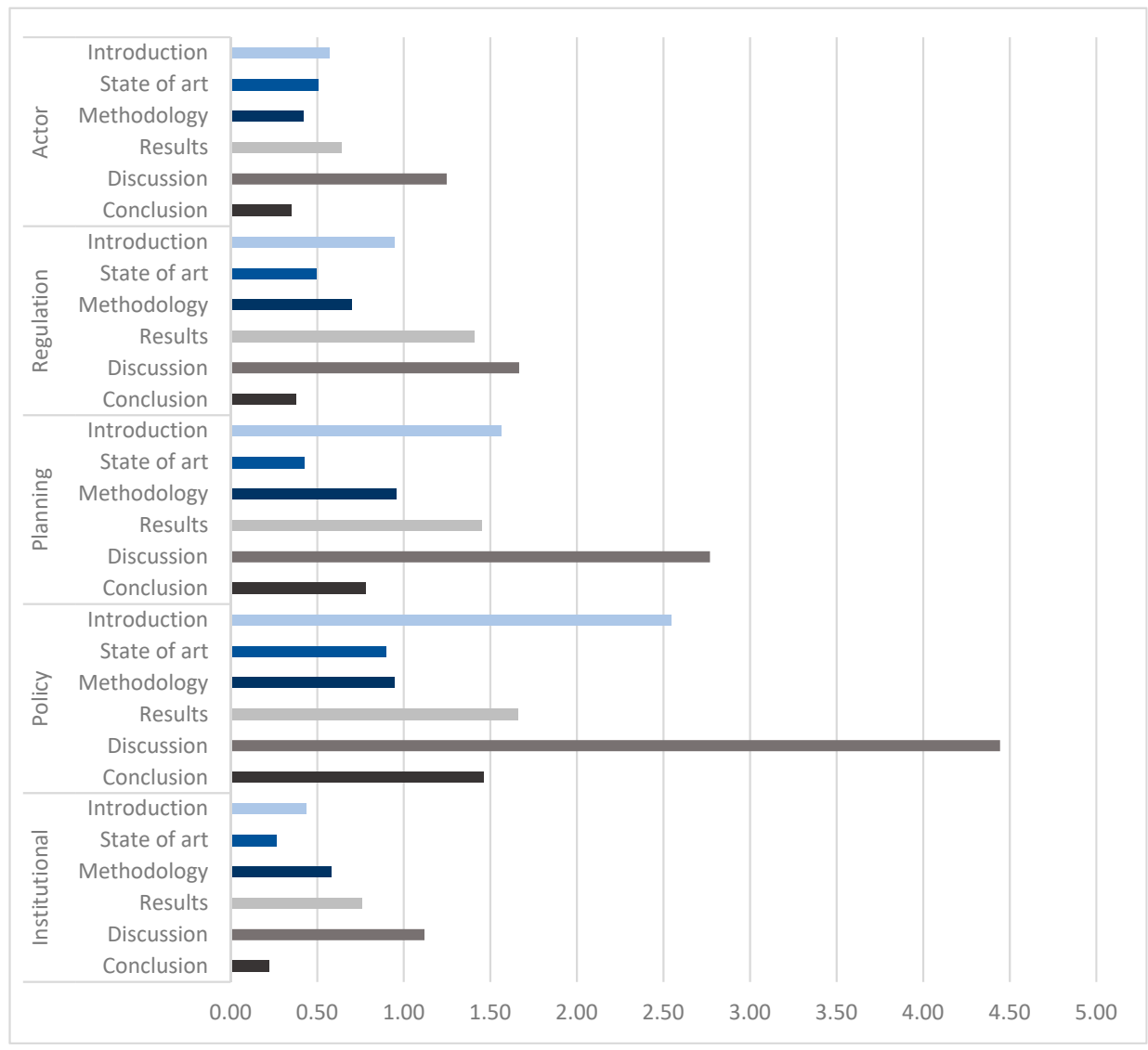

Figure 6. Mean value of terms by major category of terms and section, per article.

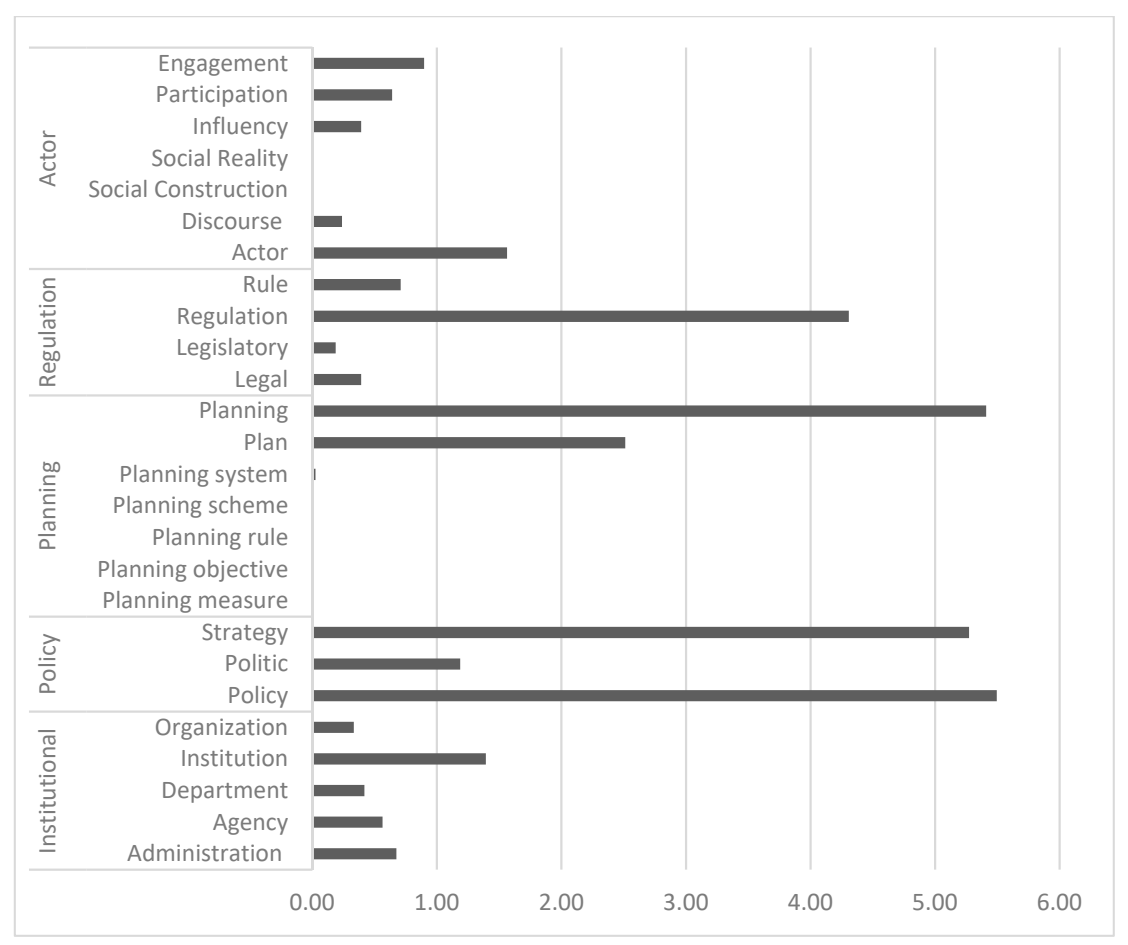

Figure 7. Mean value of each individual term per article. 
In accordance with this fact, the high use of the term regulation (about four times per article) is not followed by more precise terms such as rule or legal. Additionally, note that, although policy and strategy are terms frequently mentioned in general (mean values higher than five references per article), the term politic is much less referenced (1.21 per article). Figure 7 reinforces the poor use of terms related to both actors and institutions when compared with other terms.

Considering the distribution of terms, Figure 8 shows the percentage of articles that mention each term. In line with the previous results, the term strategy is abundantly used in literature (occurrence in more than $70 \%$ of articles), while also the terms regulation, planning, and policy are frequently used (more than $60 \%$ of articles).

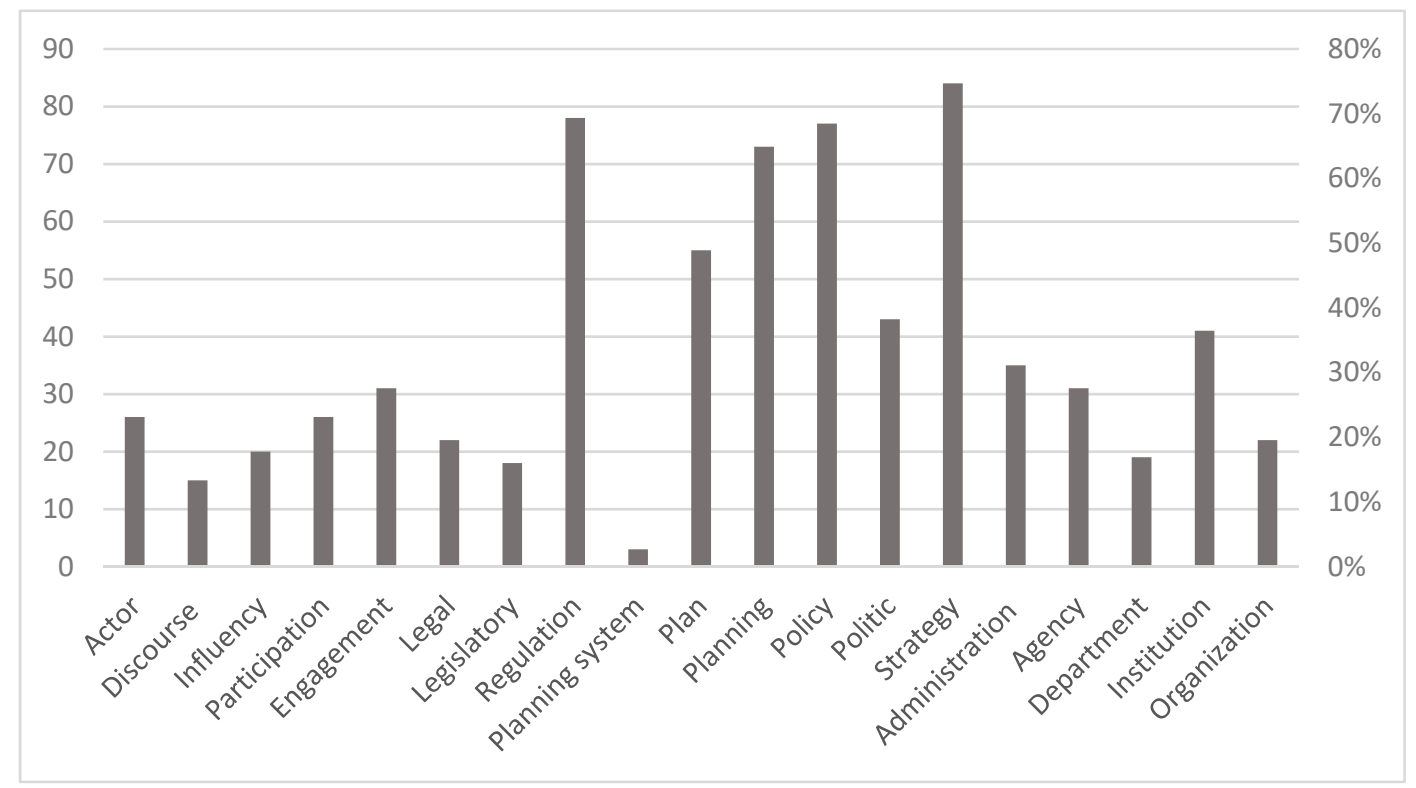

Figure 8. Total number of articles (left axis) and percentage (right axis) of occurrence of each individual term.

Albeit the differences shown between terms become less evident in the frequency chart, the terms actor, organization, and department are referred to in less than $30 \%$ of articles and organization in just above $40 \%$. These results reinforce the predominance of strategy, regulation, and policy terms when compared with any terms of institutional category.

\subsection{Qualitative Analysis}

Following the quantitative analyses, and considering the previous results, a set of articles was selected that refers most to the terms studied. Davies et al. (2017) [49] addresses in an indirect way NBS by studying tree strategies in the UK and how they are managed to improve ecosystem services. As this study compiles contributions from various technicians of the municipalities under analysis, the produced discourse regarding strategy and planning issues is much more common. The subject of governance is also present, as the authors refer (p. 7) "Without a formal tree strategy- or other tree-related policies of strategic nature-tree officers have little or no involvement in delivering their council's".

In line with this study, Schubert et al. (2018) [50] address the issue of ecosystem services and the way they have been incorporated in the Swedish planning context. Some references are made to NBS, mostly under the umbrella of ecosystem service as a related term. The use of the terms as plan or planning is very frequent, with indirect importance given to the issue of governance at the municipal scale. Governance is, also here, referred as an important issue to be addressed as the authors point out (p. 12): "Although our interviews have shown that most relevant stakeholders seem to be familiar 
with the ES concept, they also indicate that further support is needed for translating this knowledge into actual implementation".

Hence, planning is a commonly used term, even though allowing multiple interpretations, within and outside the spectrum of planning in the territorial context. One good example is the work by Zölch et al. (2018) [38], where planning is the key issue addressed. As the focus is on ecosystem-based approaches (EbA), direct references to NBS are rare. Again, the articulation between governance and implementation is highlighted, with concrete references such as on (p. 9) "( . . ) the successful translation of EbA measures into strategic adaptation planning and practice needs further mainstreaming at all levels".

The work of van der Jagt et al. (2017) [51] is one of the papers with more references to the terms in study, with particular focus on the governance issues of communal urban gardens. Here, the interpretation of NBS is associated with the concept of communal urban gardens. Governance and planning aspects are referred to in various ways, such as (p. 8) " (... community groups benefited from internally agreed and clearly formulated objectives, rules, and governance procedures" or (p. 9) " (... ) urban agriculture was often an element of more generic urban green plans or spatial planning documents". Institutional arrangements are often mentioned, with participation and stakeholders considered as important subjects.

Connop et al. (2015) [34] use NBS as an umbrella concept for, in this case, urban green infrastructures (UGI). Planning, policy, and strategy are terms commonly used, as for example on (p. 8) "Adaptation to climate is an issue in urban and landscape planning however the formal planning system does not yet promote experimental adaptation measures". The embedment of urban green infrastructures is also an issue addressed in this paper, such as on (p. 10) "( . . ) to incorporate knowledge exchange and collaboration with key stakeholders so that strategic and applied approach to incorporating UGI as an integral part of city planning can be implemented".

The paper of Camps-Calvet et al. (2015) [52] comprehends the concept of nature-based solutions as framed in the concept of urban gardens. There is an emphasis on the importance of policy, plans, and regulations, as for example discussed on (p. 8) “( . . ) nature-based solutions for urban policies aiming at enhanced human well-being $(\ldots)$ ". This work is very much focused on the comprehension of urban gardens as promotors of social inclusion, while governance is indirectly addressed as a key issue.

\section{Discussion}

The results shown above prove that the concept of nature-based solutions has increased in the past years and is expected to continue to increase. The financial support given by multiple institutions through research incentives is promoting this subject, and here the European Comission is the key actor responsible for this growth. This aspect is reinforced by the high amount of authorships shared by European countries and the relative lack of connections with other continents. These results prove that greater attention must be given to countries in other regions of the globe, such as Latin America, Africa, and Asia. These regions will be widely exposed to climate change with the emergence of megacities and an increasingly urban population.

The NBS literature clearly shows a tendency to 'shadow' the term in detriment of other terms, such as ecosystem services, ecosystem-based approaches, and green infrastructure. While these terms have a profound relation with NBS, they are not the same-i.e., various authors refer to this as an evolving metaphor initiating in ecosystem services, passing through green infrastructures and more recently to NBS [27]. In addition, some authors argue that NBS emerged as a way to operationalize the ecosystem services concept in planning and policy practices [53]. Evolution presupposes change and therefore NBS can use the learning from other "environmental metaphors" overcoming the common difficulties presented by other terms. Nevertheless, even the definition of NBS as a concept continues to be discussed-for some authors the interpretation of NBS is more general (allowing for interpretations, such as, for example, considering NBS as any structure that mimics nature), while for other authors, the NBS concept is more narrow (e.g., only considering natural structures as nature-based solutions). 
The continuous growth of publications on NBS is not followed by such a prominent increase in publications on this subject in the areas of governance and land-use. This pattern of publication can be explained by an increased interest in topics such as environmental indicators, in comparison with other discussions such as governance, implementation, and institutionalization issues. In fact, as Frantzeskaki et al. (2019) [22] indicate, research on NBS is more focused on single case studies and their multiple benefits rather than on planning, governance, and other subjects related to their implementation [25,33]. In accordance with, Ojea et al. (2015) [54] addresses the poor governance structures as a key problem in the issue of ecosystem-based adaptation, and Kremer et al. (2016) [55] identifies the lack of articulation between science and policy as an essential barrier to embed ecosystem services in decision-making.

Simultaneously, and in what could be interpreted as an inconsistency, this study shows the frequent use of planning and policy related terms in the NBS specific literature (see Figures 4 and 7). This is not a surprise since, as discussed in the introduction, the NBS topic was vastly promoted by supranational institutions such as the European Comission. Therefore, the overall discourse regarding NBS tends to be more focused on operationalization since financing incentives and case studies are common. Nevertheless, more specific terms, as planning measures are missing—proving a general trend in the scientific community to discuss the issue of planning in more general and therefore vague terms. This is also highlighted by the relatively less attention given to institutional related terms, being those essential to promote the efficient embedding in planning structures. Despite this fast institutional incorporation at the European level, nature-based solutions continue to suffer the same implementation problems as other environmental concepts, such as ecosystem services, green infrastructures, or ecosystem-based approaches. As a result, the institutionalization of NBS at national and local levels is still difficult to achieve beyond very focused case study projects.

When first emerged, NBS served as an umbrella for various concepts linked to the replication of functions offered by nature. Yet, as noted above, the rapid growth of publications brought new definitions, contributing to complexify the original understanding. Although this capability of merging different concepts may be positive [56], it can also hinder a thorough assessment of concrete governance and planning experiences [57]. It is fair to state that NBS is nowadays a vaguer concept in comparison to its earlier versions. The increase in the number of definitions, and consequent dispersion, may have deterred the building of the narratives required to assess their incorporation at the governance and planning levels. Within the umbrella of NBS, there are many different concepts ranging from green belts to green roofs or walls, ecosystem services, blue and green infrastructures, and many others. These are always considered as components of the NBS discourse. The NBS literature, however, does not always cover them under the overall concept. In practice what is being implemented, and therefore studied, is not the umbrella concept of NBS, but mostly particular components of NBS such as green or blue infrastructures. This may explain the lesser attention given to governance and planning concerns in the NBS literature. Following the contributions from van der Jagt et al. (2019) [58], there is an evident need to further explore the link between the literature on NBS and the planning and governance learnings acquired with the implementation of particular NBS components. A critical discussion on normative approaches for NBS could also shed new lights into the governance and planning fields.

As seen here, the scientific discourse on NBS is still struggling to deliver specific planning, governance, and institutional recommendations that can embed these solutions in the decision-making process and in specific planning tools. Consequently, the incorporation of NBS in the urban agenda is essential to move towards a more sustainable planning approach. Furthermore, the incorporation of these concepts in policy and planning instruments, such as municipal master plans, in a clear and comprehensive way presents as an essential move that must be promoted by both social and environmental scientists $[59,60]$.

The importance of recognizing the limitations of studies such as the one presented here is pertinent. In particular, content analysis and the counting of selected terms are exposed to both software and researcher limitations. The methodical approach taken in the present study, assuming counting terms in 
dubious cases, may be questioned. However, assumptions have been made explicit giving transparency to the used, considering more terms in order to incorporate more interpretations of the text. Thus, the analysis dimension, with more than 4000 terms considered in 132 papers, gives robustness to the study aiming to uncover the major tendencies that are conducting and influencing the scientific literature on nature-based solutions.

\section{Conclusions}

The emerging of nature-based solutions (NBS) can bring innovative solutions to new challenges that cities are facing in terms of climate change and biodiversity losses. This emergence also proofs that other concepts, such as ecosystem services or green/blue spaces, were not yet fully embedded in planning processes and, therefore, in decision-making. The aim of this paper was to understand how the scientific community is developing the NBS topic and addressing the issues of actors, regulations, planning, policy, and institutions. The present work demonstrates the importance of policy and planning in the discourse among the literature in this area, influenced by the initial promotion by the European Commission that was, and continues to be, predominantly orientated to planning, economy, and decision-making. The growing number of publications is evident and is expected to increase over the next decade, given the continued research and/or innovation investments in this topic. This boom in publications is natural in concepts that are recent and rapidly became the spotlight.

In conclusion, the discourse presented by the analysed literature follows an initial pattern, common in other environmental concepts-being more general, often vaguer and more centered in the Introduction and Discussion sections. There is a lack of literature pointing towards the importance of institutions and administrative units to promote efficient incorporation of nature-based solutions. The next years are decisive for the success of NBS, not only as a concept but also as a "wind of change" in the form of governance. Quantitative approaches that solidify the interest of NBS for technicians and decision-makers are important, but we cannot forget to adapt institutions and forms of governance in order to foster the incorporation of NBS into urban planning.

Author Contributions: Conceptualization, R.M., T.F., P.R., and F.T.; Data collection, R.M.; Methodology, R.M., T.F., and F.T.; Interpretation of results, R.M., T.F., P.R., and F.T.; Formal analysis, R.M.; Writing-original draft preparation, R.M.; Writing-review and editing, R.M., T.F., and P.R. All authors have read and agreed to the published version of the manuscript.

Funding: This paper has been developed in the context of the UNaLab Project (https://www.unalab.eu/), which has received funding from the European Union Horizon 2020 research and innovation programme under Grant Agreement No. 730052, Topic: SCC-2-2016-2017: Smart Cities and Communities Nature-based solutions. Thanks are also due for the financial support to CESAM (UID/AMB/50017/2019), to GOVCOPP (project POCI-01-0145-FEDER-008540), to FCT/MCTES through national funds, and the co-funding by the FEDER, within the PT2020 Partnership Agreement and Compete 2020.

Conflicts of Interest: The authors declare no conflict of interest.

\section{References}

1. United Nations. Department of Economic and Social Affairs, Population Division. World Urbanization Prospects: The 2014 Revision; ST/ESA/SER.A/366; United Nations: New York, NY, USA, 2015.

2. IPCC. Climate Change 2014: Synthesis Report. Contribution of Working Groups I, II and III to the Fifth Assessment Report of the Intergovernmental Panel on Climate Change; Core Writing Team, Pachauri, R.K., Meyer, L.A., Eds.; IPCC: Geneva, Switzerland, 2014; p. 151.

3. Revi, A.; Satterthwaite, D.E.; Aragón-Durand, F.; Corfee-Morlot, J.; Kiunsi, R.B.R.; Pelling, M.; Roberts, D.C.; Solecki, W. Urban areas. In Climate Change 2014: Impacts, Adaptation, and Vulnerability. Part A: Global and Sectoral Aspects. Contribution of Working Group II to the Fifth Assessment Report of the Intergovernmental Panel on Climate Change; Field, C.B., Barros, V.R., Dokken, D.J., Mach, K.J., Mastrandrea, M.D., Bilir, T.E., Chatterjee, M., Ebi, K.L., Estrada, Y.O., Genova, R.C., et al., Eds.; Cambridge University Press: Cambridge, UK; New York, NY, USA, 2014; pp. 535-612. 
4. Wamsler, C. Cities, Disaster Risk and Adaptation, Routledge Series on Critical Introduction to Urbanism and the City; Routledge: London, UK, 2013.

5. Schroter, D. Ecosystem service supply and vulnerability to global change in Europe. Science 2005, 310, 1333-1337. [CrossRef]

6. Grimm, N.B.; Faeth, S.H.; Golubiewski, N.E.; Redman, C.L.; Wu, J.; Bai, X.; Briggs, J.M. Global change and the ecology of cities. Science 2008, 319, 756-760. [CrossRef] [PubMed]

7. Pontee, N.; Beck, M.W.; Hosking, A.H. Nature Based Solutions: Lessons from around the world. Proc. Inst. Civ. Eng. Marit. Eng. 2016, 169, 651-661. [CrossRef]

8. Riechers, M.; Jan, B.; Teja, T. Perceptions of cultural ecosystem services from urban green. Ecosyst. Serv. 2016, 17, 33-39. [CrossRef]

9. Haase, D. Greening cities-To be socially inclusive? About the alleged paradox of society and ecology in cities. Habitat Int. 2017, 64, 41-48. [CrossRef]

10. European Commission (EC). Europe 2020: A Strategy for Smart, Sustainable and Inclusive Growth. Working Paper; COM (2010) 2020; European Commission: Brussels, Belgium, 2010.

11. Bauduceau, N. Towards an EU Research and Innovation Policy Agenda for Nature-based Solutions E Re-Naturing Cities: Final Report of the Horizon 2020 Expert Group on Nature-Based Solutions and Re-Naturing Cities; European Commission: Brussels, Belgium, 2015.

12. European Commission. An EU Biodiversity Strategy to 2020. Communication from the Commission to the European Parliament, the Council, the European Economic and Social Committee and the Committee of the Regions; COM (2011)244final; European Commission: Brussels, Belgium, 2011.

13. European Commission. Green Infrastructure (GI)_Enhancing Europe's Natural Capital. Communication from the Commission to the European Parliament, the Council, the European Economic and Social Committee and the Committee of the Regions; COM (2013); European Commission: Brussels, Belgium, 2013.

14. Maes, J.; Jacobs, S. Nature-Based Solutions for Europe's Sustainable Development. Conserv. Lett. 2017, 10, 121-124. [CrossRef]

15. Raymond, C.M.; Berry, P.; Breil, M.; Nita, M.R.; Kabisch, N.; de Bel, M.; Enzi, V.; Frantzeskaki, N.; Geneletti, D.; Cardinaletti, M.; et al. An Impact Evaluation Framework to Support Planning and Evaluation of Nature-Based Solutions Projects, Report Prepared by the EKLIPSE Expert Working Group on Nature-Based Solutions to Promote Climate Resilience in Urban Areas; Centre for Ecology \& Hydrology: Wallingford, UK, 2017.

16. Eggermont, H. Nature-based Solutions: New Influence for Environmental Management and Research in Europe. GAIA Ecol. Perspect. Sci. Soc. 2015, 24, 243-248. [CrossRef]

17. European Commission. Nature-Based Solutions|Environment-Policy Topics. 2016. Available online: https://ec.europa.eu/research/environment/index.cfm?Pg=nbs (accessed on 21 June 2019).

18. Dennis, M.; James, P. Urban Forestry \& Urban Greening User participation in urban green commons: Exploring the links between access, voluntarism, biodiversity and well being. Urban For. Urban Green. 2016, $15,22-31$.

19. Ugolini, F. Land Use Policy Knowledge transfer between stakeholders in the field of urban forestry and green infrastructure: Results of a European survey. Land Use Policy 2015, 49, 365-381. [CrossRef]

20. Hansen, R. The uptake of the ecosystem services concept in planning discourses of European and American cities. Ecosyst. Serv. 2015, 12, 228-246. [CrossRef]

21. Frantzeskaki, N.; Borgström, S.; Gorissen, L.; Egermann, M.; Ehnert, F. Nature-Based Solutions Accelerating Urban Sustainability Transitions in Cities: Lessons from Dresden, Genk and Stockholm Cities; Springer: Cham, Switzerland, 2017; pp. 65-88.

22. Frantzeskaki, N. Seven lessons for planning nature-based solutions in cities. Environ. Sci. Policy 2019, 93, 101-111. [CrossRef]

23. Kabisch, N.; Korn, H.; Stadler, J.; Bonn, A. Nature-Based Solutions to Climate Change Adaptation in Urban Areas_Linkages between Science, Policy and Practice. Theory and Practice of Urban Sustainability Transitions; Springer: Cham, Switzerland, 2017; pp. 1-11.

24. Cohen-Shacham, E.; Walters, G.; Janzen, C.; Maginnis, S. Nature-Based Solutions to Address Global Societal Challenges; IUCN: Gland, Switzerland, 2016; p. 97.

25. Nesshöver, C. The science, policy and practice of nature-based solutions: An interdisciplinary perspective. Sci. Total Environ. 2017, 579, 1215-1227. [CrossRef] [PubMed] 
26. Raymond, C.M. A framework for assessing and implementing the co-benefits of nature-based solutions in urban areas. Environ. Sci. Policy 2017, 77, 15-24. [CrossRef]

27. Escobedo, F.J.; Giannico, V.; Jim, C.Y.; Sanesi, G.; Lafortezza, R. Urban forests, ecosystem services, green infrastructure and nature-based solutions: Nexus or evolving metaphors? Urban For. Urban Green. 2019, 37, 3-12. [CrossRef]

28. Howlett, M.; Cashore, B. The Dependent Variable Problem in the Study of Policy Change: Understanding Policy Change as a Methodological Problem. J. Comp. Policy Anal. Res. Pract. 2009, 11, 33-46. [CrossRef]

29. Faivre, N.; Fritz, M.; Freitas, T.; de Boissezon, B.; Vandewoestijne, S. Nature-Based Solutions in the EU: Innovating with nature to address social, economic and environmental challenges. Environ. Res. 2017, 159, 509-518. [CrossRef]

30. Santiago Fink, H. Human-nature for climate action: Nature-based solutions for urban sustainability. Sustainability 2016, 8, 254. [CrossRef]

31. Wamsler, C. Operationalizing ecosystem-based adaptation: Harnessing ecosystem services to buffer communities against climate change. Ecol. Soc. 2016, 1, 31. [CrossRef]

32. Wolfram, M.; Frantzeskaki, N. Cities and Systemic Change for Sustainability: Prevailing Epistemologies and an Emerging Research Agenda. Sustainability 2016, 8, 144. [CrossRef]

33. Kabisch, N. Nature-based solutions to climate change mitigation and adaptation in urban areas: Perspectives on indicators, knowledge gaps, barriers, and opportunities for action. Ecol. Soc. 2016, 21, 39. [CrossRef]

34. Connop, S. Renaturing cities using a regionally-focused biodiversity-led multifunctional benefits approach to urban green infrastructure. Environ. Sci. Policy 2015, 62, 99-111. [CrossRef]

35. Davies, C.; Hansen, R.; Rall, E.; Pauleit, S.; Lafortezza, R.; Bellis, Y.; Santos, A.; Tosics, I. Green Infrastructure Planning and Implementation-The Status of European Green Space Planning and Implementation Based on an Analysis of Selected European City-Regions; EU FP7 Project GREEN SURGE, deliverable D5.1; 2015. [CrossRef]

36. Specht, K.; Zoll, F.; Siebert, R. Application and evaluation of a participatory 'open innovation' approach (ROIR): The case of introducing zero-acreage farming in Berlin. Landsc. Urban Plan. 2016, 151, 45-54. [CrossRef]

37. Brink, E. Cascades of green: A review of ecosystem-based adaptation in urban areas. Glob. Environ. Chang. 2016, 36, 111-123. [CrossRef]

38. Zölch, T.; Wamsler, C.; Pauleit, S. Integrating the ecosystem-based approach into municipal climate adaptation strategies: The case of Germany. J. Clean. Prod. 2018, 170, 966-977. [CrossRef]

39. Xing, Y.; Jones, P.; Donnison, I. Characterisation of nature-based solutions for the built environment. Sustainability 2017, 9, 149. [CrossRef]

40. Vandergert, P.; Collier, M.; Kampelmann, S.; Newport, D. Blending adaptive governance and institutional theory to explore urban resilience and sustainability strategies in the Rome metropolitan area, Italy. Int. J. Urban Sustain. Dev. 2016, 8, 126-143. [CrossRef]

41. Andersson, E.; Tengö, M.; McPhearson, T.; Kremer, P. Cultural ecosystem services as a gateway for improving urban sustainability. Ecosyst. Serv. 2015, 12, 165-168. [CrossRef]

42. Frantzeskaki, N.; Kabisch, N.; McPhearson, T. Advancing urban environmental governance: Understanding theories, practices and processes shaping urban sustainability and resilience. Environ. Sci. Policy 2016, 62, 1-6. [CrossRef]

43. Gulsrud, N.M.; Hertzog, K.; Shears, I. Innovative urban forestry governance in Melbourne?: Investigating 'green placemaking' as a nature-based solution. Environ. Res. 2018, 161, 158-167. [CrossRef]

44. Van Eck, N.; Waltman, L. Software survey: VOSviewer, a computer program for bibliometric mapping. Scientometrics 2010, 84, 523-538. [CrossRef]

45. Fortunato, S. Community detection in graphs. Phys. Rep. 2010, 486, 75-174. [CrossRef]

46. Caschili, S.; de Montis, A.; Ganciu, A.; Ledda, A.; Barra, M. The Strategic Environment Assessment bibliographic network: A quantitative literature review analysis. Environ. Impact Assess. Rev. 2014, 47, 14-28. [CrossRef]

47. Phillips, N.; Lawrence, T.B.; Hardy, C. Discourse and institutions. Acad. Manag. Rev. 2004, 29, 636-652. [CrossRef]

48. Van den Bosch, M.; Sang, A.O. Urban natural environments as nature-based solutions for improved public health-A systematic review of reviews. Environ. Res. 2017, 158, 373-384. [CrossRef] 
49. Davies, H.J.; Doick, K.J.; Hudson, M.D.; Schreckenberg, K. Challenges for tree officers to enhance the provision of regulating ecosystem services from urban forests. Environ. Res. 2017, 156, 97-107. [CrossRef]

50. Schubert, P. Implementation of the ecosystem services approach in Swedish municipal planning. J. Environ. Policy Plan. 2018, 20, 298-312. [CrossRef]

51. Van der Jagt, A.P.N. Cultivating nature-based solutions: The governance of communal urban gardens in the European Union. Environ. Res. 2017, 159, 264-275. [CrossRef]

52. Camps-Calvet, M.; Langemeyer, J.; Calvet-Mir, L.; Gómez-Baggethun, E. Ecosystem services provided by urban gardens in Barcelona, Spain: Insights for policy and planning. Environ. Sci. Policy 2015, 62, 14-23. [CrossRef]

53. Scott, M. Nature-based solutions for the contemporary city/Re-naturing the city/Reflections on urban landscapes, ecosystems services and nature-based solutions in cities/Multifunctional green infrastructure and climate change adaptation: Brownfield greening as an adaptation strategy for vulnerable communities?/Delivering green infrastructure through planning: Insights from practice in Fingal, Ireland/Planning for biophilic cities: From theory to practice. Plan. Theory Pract. 2016, 17, 267-300.

54. Ojea, E. Challenges for mainstreaming Ecosystem-based Adaptation into the international climate agenda. Curr. Opin. Environ. Sustain. 2015, 14, 41-48. [CrossRef]

55. Kremer, P. Key insights for the future of urban ecosystem services research. Ecol. Soc. 2016, 21, 29. [CrossRef]

56. Dorst, H.; van der Jagt, A.; Raven, R.; Runhaar, H. Urban greening through nature-based solutions-Key characteristics of an emerging concept. Sustain. Cities Soc. 2019, 49, 101620. [CrossRef]

57. McCormick, K.; Anderberg, S.; Coenen, L.; Neij, L. Advancing sustainable urban transformation. J. Clean. Prod. 2013, 50, 1-11. [CrossRef]

58. Van der Jagt, A.P.N.; Raven, R.; Dorst, H.; Runhaar, H. Nature-based innovation systems. Environ. Innov. Soc. Trans. 2019. [CrossRef]

59. Zwierzchowska, I.; Fagiewicz, K.; Poniży, L.; Lupa, P.; Mizgajski, A. Introducing nature-based solutions into urban policy-Facts and gaps. Case study of Poznań. Land Use Policy 2019, 85, 161-175. [CrossRef]

60. Lafortezza, R.; Sanesi, G. Nature-based solutions: Settling the issue of sustainable urbanization. Environ. Res. 2019, 172, 394-398. [CrossRef]

(C) 2020 by the authors. Licensee MDPI, Basel, Switzerland. This article is an open access article distributed under the terms and conditions of the Creative Commons Attribution (CC BY) license (http://creativecommons.org/licenses/by/4.0/). 